\title{
$\operatorname{ATUAII} A \backslash C \mathrm{~A} O$
}

\section{ABORDAGEM CLÍNICO-IMUNOLÓGICA DA INFECÇÃO GRAVE POR HANTAVÍRUS}

\section{Klitia de Jesus Saraiva Garrido Carneiro ' e Cloves Silva Carneiro ${ }^{2}$}

\section{RESUMO}

No contexto da abordagem clínico-imunológica da infecção por hantavírus em sua forma mais severa, a síndrome pulmonar por hantavírus (SPH), são descritas as principais características do agente etiológico e sua repercussão no organismo após o processo de invasão. Ressalta-se o papel desempenhado pela resposta imune do hospedeiro e seu possível envolvimento na patogênese da doença.

DESCRITORES: Hantavirose. Síndrome pulmonar por hantavírus. Sistema imune.

\section{INTRODUÇÃO}

As hantaviroses são infecções zoonóticas amplamente distribuídas em todo o mundo, constituindo-se num importante problema de saúde pública na Ásia e Europa. Representam o protótipo das doenças emergentes, ocorrendo em diversos países do continente americano, inclusive no Brasil (Ruo et al. 1994, Satcher 1995, Mascarenhas-Batista et al. 1998, Ferreira 2003). São enfermidades agudas, contraídas pelo homem através da inalação de partículas virais eliminadas nas fezes e na urina de roedores domésticos e silvestres. As infecções humanas causadas pelos hantavírus se manifestam sob diferentes formas, desde doença febril aguda, cuja suspeita diagnóstica é baseada fundamentalmente em informações epidemiológicas, até quadros pulmonares e cardiovasculares mais càracterísticos, como a síndrome pulmonar por hantavírus (SPH). Eventualmente apresenta-se sob a forma de febre hemorrágica com comprometimento renal (FHCR ou HFRS, hemorragic fever with renal syndrome).

1 Departamento de Saúde Pública da Universidade Federal do Maranhão (UFMA).

2 Clínica Geral, Infectologia e Medicina do Trabalho, São Luís, MA

Endereço para correspondência: Klitia de Jesus S. G. Carneiro, Departamento de Saúde Pública, UFMA, Rua Barão Itapary, 155, Centro, São Luís, MA, CEP: 65020-070. E-mail: klitia@elo.com.br

Recebido para publicação em 14/8/2003. Revisto em 1/3/2004. Aceito em 8/11/2004. 
A SPH é uma doença emergente e tem sido, até o momento, a forma prevalente nas Américas (Funasa 2002, Galeno et al. 2002). No Brasil, no período de novembro de 1993 a julho de 2002, foram notificados ao Cenepi-Funasa 210 casos confirmados em laboratório. $\mathrm{O}$ agente etiológico é o vírus Hantaan, da familia Bunyaviridae, o qual constitui um "supergrupo" subdividido em cinco gêneros, com base em características estruturais e bioquímicas: Bunyavirus, Phlebovirus, Nairovirus, Uukuvirus e Hantavirus.

Os hantavirus possuem, no mínimo, catorze espécies distintas de vírus identificados, cada uma com um vetor e distribuição geográfica específicos. Dentre as espécies, destacam-se: Hantaan (HTN), Seoul (SEO), Dobrava (DOB) e Puumala (PUUV), produzindo FHCR como enfermidade humana. Induzindo SPH, destacam-se as espécies Sin Nombre (SNV), New York (NY), Black Creek Canal (BCC) e Bayou (BAY). Existem ainda aquelas que não causam enfermidade conhecida, dentre elas as espécies Thailand (THAI), Prospect Hill (PH), Thottapalayam (TPM) e El Moro Canyon (ELMC) (Schmaljohn \& Hjelle 1997, Funasa 2002).

Os Hantavirus possuem RNA de hélice simples como ácido nucléico. São vírus portadores de envelope, e seu RNA apresenta três segmentos, designados de pequeno, médio e grande. $\mathrm{O}$ pequeno codifica a proteína $\mathrm{N}$ do nucleocapsídio, o médio codifica uma glicoproteína precursora que, quando clivada, gera as duas proteínas do envelope (G1 e G2) e, finalmente, o segmento maior codifica a proteína $\mathrm{L}$, que apresenta funções de transcriptase/replicase viral (Murray et al. 2000, Ferreira 2003).

Segundo Ferreira (2003), a taxa de letalidade da hantavirose americana alcança $50 \%$. Corroborando o diagnóstico da infecção, existe uma coincidência da resposta imune com os sintomas iniciais, que envolvem a presença precoce de várias citocinas e de marcadores inflamatórios, além da ativação de células $\mathrm{T}$ no sangue periférico. As provas sorológicas, principalmente imunoenzimáticas, são largamente utilizadas para a identificação de anticorpos específicos. Usualmente, o diagnóstico de exclusão da hantavirose pode ser obtido por uma simples dosagem de anticorpos IgM específicas para hantavírus (Plyusnin et al. 1996, Ferreira 2003). Essa virose apresenta uma efetiva resposta imune já desenvolvida no início dos sintomas, incluindo altos níveis de anticorpos específicos.

Segundo dados da Funasa (2002), todas as pessoas parecem ser suscetíveis. Há relatos de infecção assintomática ou moderada, sem comprometimento cardiopulmonar. As reinfecções no homem não têm sido observadas. A proteção e a duração da imunidade conferida pela infeç̧ão prévia são desconhecidas.

Esta atualização procurou descrever alguns aspectos relativos à resposta imunológica do hospedeiro ante as manifestações clínicas da doença, com especial ênfase nos casos graves desenvolvidos na SPH. 


\section{SPH: RESPOSTA IMUNE HUMANA VERSUS GRAVIDADE DA DOENÇA}

Em 1993, no sudoeste dos Estados Unidos, surgiram os primeiros casos da síndrome de distress respiratório do adulto (SDRA ou ARDS, adult respiratory distress syndrome), cujo agente etiológico responsável era o hantavírus da espécie Sin Nombre (SNV). Tratava-se de uma nova doença respiratória aguda: a SPH, cujo quadro clínico é insidioso, com evolução para poliúria, que, na maioria dos casos, antecipa o início da recuperação. Desde então, essa síndrome tem sido identificada em outras partes do globo. A sindrome cardiopulmonar por hantavírus, uma doença emergente, tem sido, até o momento, a forma prevalente nas Américas. Inicialmente, na descrição da hantavirose do Novo Mundo, ressaltou-se apenas o grande comprometimento pulmonar. Depois, foi descrito o comprometimento cardíaco importante, a partir da publicação dos primeiros casos da América do Sul (Funasa 2002).

A SPH apresenta uma alta taxa de mortalidade, de $40 \%$ a $45 \%$, além de sintomas análogos aos da influenza, progredindo rapidamente para um quadro de insuficiência respiratória aguda, em decorrência de um infiltrado pulmonar bilateral (Nolte et al. 1995, Zaki et al. 1995).

As hantaviroses causam doença no homem, mas não nos animais hospedeiros, e tanto as hantaviroses patogênicas como as não patogênicas têm o mesmo tropismo tecidual, replicando-se predominantemente nas células endoteliais e nos macrófagos. As células endoteliais infectadas não são lisadas pelos hantavírus pois o vírus por si só não é citopático e, embora as células da resposta imune sejam recrutadas para o local da infecção endotelial, não está ainda totalmente esclarecido o que determina o intenso comprometimento vascular da doença (Nolte et al. 1995, Galeno et al. 2002).

A gravidade da doença aumenta a partir do surgimento da resposta imune (Ferreira 2003). Os mecanismos patogênicos das infecções pelo hantavirus que levam à FHCR ou SPH parecem originar da resposta imune exagerada a esses microrganismos.

$\mathrm{Na} \mathrm{SPH}$, estudos imuno-histoquímicos em tecido pulmonar mostram a extensa distribuição de antígenos virais em células endoteliais, sem evidências de necrose celular. Os antígenos virais também encontram-se presentes em outros órgãos, tais como o coração e o tecido linfóide. Nos pulmões, há infiltração considerável de linfócitos TCD8+, que também aparecem no sangue periférico, sob a forma de linfócitos atípicos. Essas células, depois de ativadas, são capazes de produzir citocinas que atuarão diretamente sobre o endotélio vascular estimulando macrófagos locais a produzirem citocinas, como o fator de necrose tumoral, a interleucina $1, o$ INF- $\gamma$, o fator ativador de plaquetas e os leucotrienos, substâncias que aumentam a permeabilidade vascular (Zaki apud Ferreira 2003). 
A gravidade das manifestações clínicas dos casos de SPH é decorrente do aumento da permeabilidade vascular, da pneumonia intersticial com infiltrado de células mononucleares, do edema severo do tecido pulmonar e da trombocitopenia aguda; essa última ocorre devido à propriedade de aderência viral às plaquetas sangüíneas, através de receptores para $\mathrm{B} 3$ integrina, o que desencadeia a plaquetopenia (Nolte et al. 1995, Zaki et al. 1995).

\section{RESPOSTA IMUNE HUMORAL}

Cinética da resposta de anticorpos

A hantavirose humana induz, inicialmente, à produção de elevados niveis de IgM anti-viral específica direcionada para a proteína $(\mathrm{N})$ do nucleocapsídeo viral e para as proteínas do envelope viral, as glicoproteínas G1 e G2 (Lundkvist et al. 1993, Zöller et al. 1993).

Segundo observações de Bostik et al. (2000), anticorpos IgM antiSNV foram detectados em 100\% dos pacientes na fase aguda da infeç̧ão (SPH), em títulos elevados $(1.600-102.400)$. Nessa perspectiva, considera-se que os testes para detectar anticorpos IgM específicos podem ser amplamente utilizados no diagnóstico precoce na SPH.

A presença de anticorpos IgM, já no início dos sintomas, ou a quadruplicação dos títulos de IgG em amostras de soros pareadas confirmam a suspeita clínica. Isso é observado nas duas formas da doença: FHCR ou SPH. Os anticorpos da classe IgG persistem por toda a vida do indivíduo e podem ser utilizados em investigações, visando diagnosticar infecções passadas sintomáticas ou assintomáticas (Ferreira 2003).

Na maioria das infecções por vírus PUUV - FHCR branda - , elevados níveis de IgG e IgA específicas para a proteina $\mathrm{N}$, principalmente as subclasses IgA1, IgG1 e IgG3, podem ser precocemente detectados no início da doença (Vapalahti et al. 1995). Admite-se que, em doenças virais, as subclasses IgG1 e IgG3 são detectadas predominantemente nas infecções primárias, ao passo que as subclasses IgG2 e IgG4 são mais características das infecções recorrentes (Bostik et al. 2000). A detecção precoce de IgM, IgG e IgA (no soro e na saliva) foi demonstrada também nos pacientes infectados por vírus Andes (ANDV)SPH (Padula et al. 2000).

Pouco se conhece sobre os aspectos clínicos, laboratoriais e respostas imunes durante o período prodrômico febril ou mesmo antes do início dos sintomas da hantavirose humana. Galeno et al. (2002) apontaram que imunoglobulinas específicas IgG e IgM podem estar presentes nessa fase.

Embora uma grande maioria de pacientes tenha níveis de IgM detectáveis nas primeiras amostras de soros obtidas, nota-se ocasionalmente 
uma sororresposta IgM tardia, pelo menos na infecção por PUUV. Logo, resultados IgM negativos induzem à exclusão da infecção por hantavírus somente a partir do sexto dia de doença (Kallio-Kokko et al. 1998). Respostas de IgE específicas têm sido relatadas na infecção por PUUV, porém os níveis, relativamente baixos, não correspondem a nenhum parâmetro clínico.

De acordo com as observações de Bostik et al. (2000), a correspondência entre a concentração de anticorpos e a evolução da doença é evidente. Estudos comprovaram a resolução da doença perante um título elevado de anticorpos em soro de pacientes hospitalizados com SPH ou FHCR. Observação semelhante foi descrita por Galeno et al. (2002) ao detectarem niveis de IgM e IgG em soro de pacientes com SPH acometidos pelo vírus da espécie ANDV.

Epitopos de células B: proteína N e glicoproteínas específicas (G1 e G2)

O mapeamento de epitopos tem revelado a presença de várias regiões antigênicas, embora todas as frações da proteína $\mathrm{N}$ do PUUV sejam identificadas pelos anticorpos humanos. O mapeamento de epitopos através do uso de anticorpos monoclonais e do uso de proteínas recombinantes revelou que os epitopos, em uma maioria, estão localizados na parte aminoterminal das proteínas (Carvalho et al. 2001, Terajima et al. 2004). Em geral, o aminoácido 120 (aminoterminal) constitui a região reativa com a maioria dos soros humanos e de roedores. A deleção na porção terminal dos segmentos $\mathrm{L}, \mathrm{M}, \mathrm{S}$, particularmente no segmento $\mathrm{L}$, implica em decréscimo da replicação viral e conseqüentemente melhor prognóstico (Vapalahti et al. 1995, CDC 2004).

Estudos comparativos estão sendo iniciados com o fim de identificar diferenças entre epitopos virais, além de classes de anticorpos presentes no soro de pacientes com SPH que chegaram a óbito e de pacientes que sobreviveram à doença (Bostik et al. 2000).

Anticorpos neutralizantes

Nas hantaviroses, a resposta de anticorpos neutralizantes desenvolvese precocemente, em geral, no início da sintomatologia da doença, e pode ser o principal entrave ao isolamento do hantavírus em sangue humano, após o início da doença.

Estudos realizados a partir dos soros colhidos no dia da admissão hospitalar de pacientes com SPH detectaram anticorpos neutralizantes em todas as amostras. Esse período coincide clinicamente com o estágio de comprometimento cardiopulmonar da doença (Bharadwaj et al. 2000). Segundo Galeno et al. (2002), os anticorpos neutralizantes são pouco detectados durante a fase prodrômica, que cursa clinicamente com febricula e mialgias. 
O envelope viral de glicoproteínas $e$, presumivelmente, o principal componente responsável pela indução de resposta imune nas hantaviroses. Essa constatação baseia-se na detecção in vitro de atividade neutralizante conferida por anticorpos monoclonais, direcionados para G1 e G2, mas não para a proteína $\mathrm{N}$ (Dantas et al. 1986, Zhang et al. 1989).

Em pesquisas recentes, Terajima et al. (1999) detectaram o RNA viral por RT-PCR, sendo constatado um declínio da carga viral em pacientes ainda no período de internação hospitalar e durante o período de tratamento ambulatorial. Nessa perspectiva, deve-se considerar a hipótese de que, mesmo na presença do virus, os anticorpos neutralizantes e outras respostas imunes reduzem os niveis de viremia das hantaviroses. As respostas imunes adaptativas induzem anticorpos neutralizantes que reduzem o número de partículas virais, além de gerar células $\mathrm{T}$ citotóxicas que matam as células infectadas ( Benjamini et al. 2002).

\section{RESPOSTA IMUNE CELULAR}

Estando o vírus no interior da célula do hospedeiro, a resposta de anticorpos normalmente é insuficiente para eliminar a infecção viral. Assim, a erradicação da infecção freqüentemente requer respostas efetivas mediadas por células. Segundo Asada et al. (1987) e Yoshimatsu et al. (1993), pesquisas recentes têm sugerido o envolvimento dessas respostas na proteção contra a hantavirose.

Bostik et al. (2000) e Benjamini et al. (2002) apontam que a evolução da doença está ligada a mecanismos imunopatológicos, considerando que, em relação à SPH, grandes quantidades de antígenos virais, citocinas e células $\mathrm{T}$ $\mathrm{CD}^{+}$estão associados com células epiteliais da microcirculação pulmonar. $\mathrm{Na}$ hantavirose as proteinas são altamente imunogênicas, tendo sido mostrada uma eficiente indução da imunidade protetora em modelos animais (Lundkvist et al. 1993, Yoshimatsu et al. 1993).

A resposta imune celular adquirida resulta na produção de células $T$ $\mathrm{CD}^{+}$e CD8 $8^{+}$específicas, que são essenciais para a eliminação das infecções virais. Uma inversão da relação CD4/CD8 tem sido documentada no estágio precoce da HFRS (Chen \& Yang 1990, Bostik et al. 2000).

As células T CD8 ${ }^{+}$citotóxicas (CTL) são as principais células T efetoras contra os vírus. Geradas precocemente durante uma infecção viral, elas geralmente aparecem antes dos anticorpos neutralizantes. Podem reconhecer antígenos virais através das moléculas de classe I do complexo principal de histocompatibilidade (MHC-I) e eliminar as células hospedeiras que apresentam os antígenos virais. Foi descrita a associação de linfócitos T CD8 ${ }^{+}$, monócitos/ macrófagos e células endoteliais pulmonares, em pacientes com SPH na fase cardiopulmonar da doença (Zaki et al. 1995, Murray et al. 2000, Benjamini et al. 2002, Ferreira 2003). 
A infecção viral pode induzir a liberação de citocinas que desencadeiam respostas locais e sistêmicas. A febre e a estimulação do sistema imune representam dois desses efeitos sistêmicos. Em pacientes portadores de SPH, evidenciou-se o aumento do número de células produtoras de citocinas, nos tecidos pulmonar e esplênico (Mori et al. 1999).

Niveis plasmáticos elevados de TNF-alfa, dos receptores solúveis para TNF e das interleucinas (IL-6 e IL-10) foram observados no curso da HFCR e SPH (Linderholm et al. 1996). Mori et al. (1999) destacam a importância da produção local das citocinas na patogenia da $\mathrm{SPH}$, principalmente no que se refere ao comprometimento vascular em tecido pulmonar.

Constatou-se, em alguns estudos, a elevação dos níveis de histamina e serotonina, em conjunto com o aumento dos níveis de IgE, o que contribui para a presença de distúrbios endoteliais e vasculares observados na patogenia da doença (Sidelnikov \& Sivoraksha 1990).

\section{CONSIDERAÇÕES FINAIS}

As defesas do hospedeiro contra infecções virais consistem, principalmente, em retardar a replicação viral e, então, erradicar a infecção. A resposta viral pode ser complexa, com vários fatores afetando o resultado da interação vírus-hospedeiro, tais como - a via de entrada, o sítio de adesão, os aspectos de patogênese pelo vírus infectante e a resposta do sistema imune (Benjamini et al. 2002).

Nas hantaviroses, o papel desenvolvido pelo sistema imune no curso da infecção, principalmente no que se refere à SPH, parece contribuir para 0 desenvolvimento de um quadro clínico mais grave. Assim, apesar de ainda limitadas, algumas pesquisas já foram desenvolvidas com a finalidade de investigar, mais profundamente, as conseqüências da resposta imune na interação vírus-hospedeiro nessa infecção. Trata-se de uma questão ampla, que vem suscitando maiores debates e reflexões; afinal trata-se de uma dinâmica que poderá conduzir ao desenvolvimento de possiveis estratégias de proteção, a uma terapêutica mais eficiente e conseqüente redução da mortalidade pelos casos graves da infecção por hantavírus, que atualmente ainda têm alcançado taxas significativas.

\section{ABSTRACT}

Immunoclinical approach of severe infection by hantavirus

The aim of this review was an approach about the immunoclinical description in the hantavirus infection in its most severe form, the pulmonary hantavirus 
syndrome (PHS). Within this context, the main characteristics of the etiological agent, as well as its organic repercussion after the invasion process were described. The role played by the immune system of the host and their possible involvment in the pathogenesis of the disease was highlighted.

KEYWORDS: Hantavirus. Pulmonary hantavirus syndrome. Immune system.

\section{REFERENCIAS}

1. Asada H, Tamura M, Kondo K, Okuno Y, Takahashi Y, Dohi Y, Nagai T, Kurata T, Yamanishi K. Role of $T$ lymphocyte subsets in protection and recovery from Hantaan virus infection in mice. $J$ Gen Virol 68:1961-1069, 1987.

2. Benjamini E, Coico R, Sunshine G. Resistência e imunização às doenças infecciosas. In: Benjamini E, Coico R \& Sunshime G. Imunologia. Guanabara Koogan, Rio de Janeiro. 2002. 288p.

3. Bharadwaj M, Nofchissey R, Goade D, Koster F, Hjelle B. Humoral immune responses in the hantavírus cardiopulmonary syndrome. J. Infec Diseases 182: 43-48, 2000.

4. Bostik P, Winter J, Ksized TG, Rollin PE, Villinger F, Zaki SR, Peters CJ, Ansari AA. Sin Nombre Virus (SNV) Ig Isotype antibody response during acute and convalescent phases of Hantavirus Pulmonary Syndrome. Emerging Infectious Diseases 6: 184$187,2000$.

5. Carvalho $\mathrm{CN}$, Sallberg M, Hultgren C, Lundkvist A. T-helper and humoral responses to Puumala hantavirus nucleocapsid protein; identification of T-helper epitopes in a mouse model. J Gen Virol 82: 129-138, 2001.

6. Chen LB, Yang WS. Abnormalities of T cell immunoregulation in hemorrhagic fever with renal syndrome. J Infect Dis 161: 1016-1019, 1990

7. CDC - Centers for disease control and prevention. All About Hantaviruses. National Center for Control Disease. United States, 2004.

8. Dantas JR Jr, Okuno Y, Asada H, Tamura M, Takahashi M, Tanishita O, Takahashi Y, Kurata T, Yamanishi K. Characterization of glycoproteins of viruses causing hemorrhagic fever with renal syndrome (HFRS) using monoclonal antibodies, Virology 151:379-384, 1986 .

9. Ferreira MS. Hantaviroses. Rev Soc Bras Med Trop 36:81-96, 2003.

10. Funasa - Fundação Nacional de Saúde, Ministério da Saúde - BRASIL Guia de vigilância epidemiológica. $5^{\mathrm{a}}$ ed. Brasília. V. I, p. 385-403, 2002.

1 1. Galeno H, Mora J, Villagra E, Fernandez J, Hernandez J, Mertz G, Ramirez J. First human isolate of Hantavirus (Andes vírus) in the Américas. Emerging Infectious Diseases 8: 657-661, 2002.

12. Kallio-Kokko H, Vapalahti O, Lundkvist A, Vaheri A.. Evaluation of Puumala virus IgG and IgM enzyme immunoassays based on recombinant baculovírus expressed nucleocapsid protein for early nephropathia epidemica diagnosis. Clin Diag Virol 10:83-90, 1998.

13. Linderholm M, Ahlm C, Settergren B, Waage A, Tärnvik A. Elevated plasma levels of tumor necrosis factor (TNF)-alfa, soluble TNF receptors, interleukin (IL)-6, and IL10 in patients with hemorrhagic fever with renal syndrome. $J$ Infect Diseases 173:3843, 1996.

14. Lundkvist A, Hörling J, Niklasson B. The humoral response to Puumala virus infection (nephropathia epidemica) investigated by viral protein specific immunoassays. Arch Virol, 130: 121-130, 1993. 
15. Mascarenhas-Batista AV, Da Rosa EST, Ksiazek TG, Da Rosa APAT, Leduc JW, Pinheiro F, Tavares-Neto J. Antibodies anti-hantavirus in schoolchidren in Salvador, Bahia State, Brazil. Rev Soc Bras Med Trop 31:433-440, 1998.

16. Mori M, Tothman AL, Kurane L, Montoya JM, Nolte KB, NormanJE, Waite DC, Koster FT, Ennis FA. High levels of cytokine-producing cells in the lung tissues of patients with fatal hantavirus pulmonary syndrome. I Infect Dis 179: 295-302, 1999.

17. Murray PR, Rosenthal KS, Kobayashi GS, Pfaller MA. Bunyaviridae. In: Murray PR, Rosenthal KS, Kobayashi GS, Pfaller MA. Microbiologia Médica. Rio de Janeiro: Guanabara Koogan, 2000. 604p.

18. Nolte KB, Freddersen RM, Foucar K, Zaki SR, Koster FT, Madar D, Merlin Tl, McFeeley PJ, Umland ET, Zumwalt RE. Hantavirus pulmonary syndrome in the United States: a pathological description of a disease caused by a new agent. Hum Pathol 26:110-120, 1995.

19. Padula PJ, Rosssi CM, Della Valle MO, Martinez PV, Colavecchia SB, Edelstein A, Miguel SD, Rabinovich RD, Segura ELJ. Development and evaluation of a solid-phase enzyme immunoassay based on Andes hantavírus recombinant nucleoprotein. Med Microbiol 49:149-155, 2000.

20. Plyusnin A, Vapalahti AO, Vaheri A. Hantaviruses: genome structure, expression and evolution. $J$ Gen Virol 77: 2677-2687, 1996.

21. Ruo SL, Li Y, Tong Z, Ma QR, Lui ZL, Tang YW, Ye KL, Xu ZY, McCormick JB, Fisher-Hoch SP. Retrospective and prospective studies of hemorrhagic fever with renal syndrome in rural China. J Infect Dis 170: 527-534, 1994.

22. Satcher D. Emerging Infections: getting, ahead of the curve. Emerg Infect Dis 1: 1-6, 1995.

23. Schmaljohn C, Hjelle B. Hantaviruses: a global disease problem. Emerg Infect Dis 3: 95-103, 1997.

24. Sidelnikov YN, Sivoraksha GA. The participation of histamine and serotonin in the genesis of acute kidney failure in patients with hemorrhagic fever with renal syndrome. Urol Nefrol Mosk 4: 46-48, 1990.

25. Terajima M, Hendershot JD, Kariwa H, Koster FT, Hjelle B, Goade D. High levels of viremia in patients with the hantavirus pulmonary syndrome. J Infect Dis 180: 20302034, 1999.

26. Terajima M, Vapalahti O, Van Epps HL, Vaheri A, Ennis FA. Immune responses to Puumala virus infection and the pathogenesis of nephropatia epidemica. Micr Infect 6: 238-245, 2004.

27. Vapalahti O, Kallio-Kokko H, Närvänn A, Julkunen I, Lundkvist Ä, Plyusnin A, Lehväslaiho $H$, Brummer-Korvenkontio $M$, Vaheri A, Landinen $H$. Human B-cell epitopes of Puumala virus nucleocapsid protein, the major antigen in early serological response. J Med Virol 46: 293-303, 1995.

28. Yoshimatsu K, Yoo YC, Yoshida R, Ishihara C, Azuma I, Arikawa J. Protective immunity of Hantaan virus nucleocapsid and envelope protein studied using baculovirus expressed proteins. Arch Virol 130: 365-376, 1993.

31. Zaki S, Greer P, Coffield L, Goldssmith C, Nolte K, Foucar K, Feddersen R, Zumwalt R, Miller G, Rollin P. Hantavirus pulmonary syndrome: pathogenesis of an emerging infectious disease. Am J Pathol 146: 552-579, 1995.

32. Zhang X, Takashima I, Mori F, Hashimoto N. Comparison of virulence between two strains of Rattus serotype hemorrhagic fever with renal syndrome (HFRS) virus in newborn rats. Micro Immunol. 33:195-205, 1989.

33. Zöller L, Yang S, Gött P, Bautz EFK, Darai G. A novel $\mu$-capture EIA based on recombinant proteins for sensitive and specific diagnosis of hemorrhagic fever with renal syndrome. J Clin Microbiol 31: 1194-1199, 1993. 